\title{
Rhodium roles
}

\author{
Lars Öhrström relates the various roles played by rhodium in our daily lives, ranging from car \\ components to drugs.
}

( nce the thin electroplated rhodium coating that makes new pieces of jewellery extra bright and shiny wears off, most of us are likely to come across rhodium mainly as a crucial component in catalytic converters for cars. In these devices, metallic particles of element 45 are embedded in the porous ceramic structure of the catalyst, and its specific role is to help break down nitrogen oxides to innocuous $\mathrm{O}_{2}$ and $\mathrm{N}_{2}$.

In 1988, a year before catalytic converters became compulsory for new cars in Sweden, I encountered this otherwise silver-white noble metal in a very different form: 50 grams of a purple powder, worth half a year's pay for a graduate student. This price reflected both the fact that element 45 is typically the most expensive of the platinum group metals (PGMs), as well as the difficulty of oxidizing it into a molecular compound. Rhodium's price fluctuates according to external factors, increasing for example if car sales go up or environmental legislation gets tougher. Moreover, as its production is dominated by a few countries, notably South Africa, mining strikes or local politics may also significantly affect the world market.

The purple powder was rhodium(III) chloride, the compound that incidentally also gave the element its name, from rhodon (Greek for rose). I used it over the next five years to make various coordination compounds, including catalysts, a main use for this metal in laboratories - new organic reactions catalysed by rhodium complexes are reported every year.

Such rhodium catalysts are also used industrially, notably for making menthol (found in many consumer products such as lip balm, cough remedies, toothpaste and aftershave), as well as L-DOPA (L-3,4-dihydroxyphenylalanine) used to treat Parkinson's disease. A noteworthy aspect of these catalysts is their enantioselectivity, which is crucial

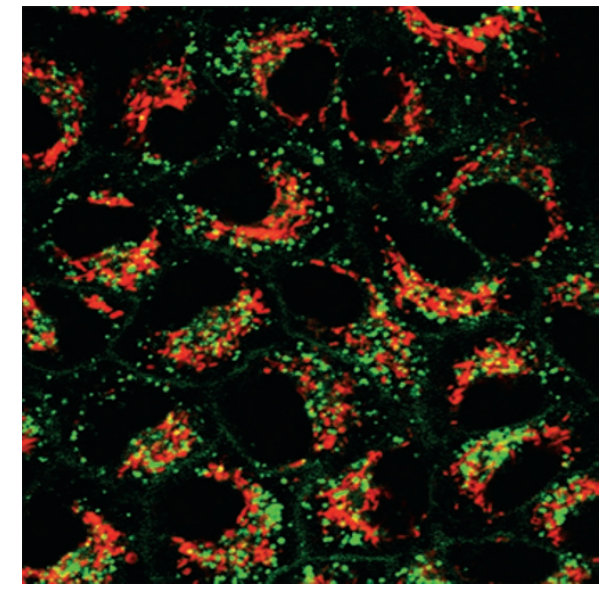

for applications, and the reason behind William S. Knowles and Ryoji Noyori sharing half of the 2001 Nobel Prize in Chemistry.

A notable feature of coordination compounds containing rhodium in oxidation state +3 is their slow release and recapture of ligands. For example, for rhodium(III) chloride dissolved in water, ten different species may form and the interchange in the octahedral coordination environment around the rhodium centre say between cis- $\left[\mathrm{RhCl}_{2}\left(\mathrm{H}_{2} \mathrm{O}\right)_{4}\right]^{+}$and trans- $\left[\mathrm{RhCl}_{2}\left(\mathrm{H}_{2} \mathrm{O}\right)_{4}\right]^{+}$- is very slow. So slow in fact that it may take a year or more for such a solution to reach chemical equilibrium. This is in sharp contrast to, for example, the $\mathrm{Fe}(\mathrm{III})$ analogue cis- $\left[\mathrm{FeCl}_{2}\left(\mathrm{H}_{2} \mathrm{O}\right)_{4}\right]^{+}$for which the corresponding cis-trans isomerization takes milliseconds.

There is a peculiar way to observe this: rhodium NMR spectroscopy ${ }^{1}$. Rhodium is one of the few elements that comes with only one isotope in nature, ${ }^{103} \mathrm{Rh}$. This isotope has the same nuclear spin $(1 / 2)$ as that of protons, and is thus excellent for NMR studies. Its poor sensitivity means that impractical amount of sample and time are often required to get a signal, which has hampered widespread use, yet it is not without proponents as Rh-coupling with other nuclei can allow valuable information to be extracted by $2 \mathrm{D}$ NMR spectroscopy techniques.

Several artificial radioactive isotopes are also known, including meta-stable nuclear isomers. One of those, ${ }^{103 \mathrm{~m} R h}$ - produced by decay from ${ }^{103} \mathrm{Ru}$ - has been investigated as a cancer therapy agent ${ }^{2}$. In light of its short half-life (59 $\mathrm{min}$ ) and the slow ligand exchange rates for $\mathrm{Rh}$ (III) complexes, however, the synthesis and use of ${ }^{103 \mathrm{~m}} \mathrm{Rh}$ compounds require careful planning.

A variety of complexes based on the $\mathrm{Rh}_{2}{ }^{4+}$ core have also shown promise as anticancer compounds. Recently, in an exciting development, a dirhodium(II) compound featuring a ligand endowed with an organic fluorophore has been shown to be taken up by cancer cells in a different manner than the free ligand ${ }^{3}$ (the dirhodium compound shows a scattered distribution in the cytoplasm, pictured). This points to new possibilities for these kinds of M-M bonded compounds and may encourage big pharmaceutical companies to step outside their organic comfort zone, just as they did 40 years ago with the development of cisplatin-type drugs based on rhodium's diagonal neighbour in the periodic table, platinum.

Although it may be in the shadow of its better-known PGM cousins, palladium and platinum, on the road of chemical applications, rhodium is gaining ground and shows no signs of slowing down.

\section{LARS ÖHRSTRÖM author of The Last}

Alchemist in Paris \& Other Curious Tales From Chemistry is in the Department of Chemistry and Chemical Engineering, Chalmers University of Technology, SE-412 96 Gothenburg, Sweden. e-mail: ohrstrom@chalmers.se

\section{Twitter: @Larsohrstrom}

\section{References}

1. Carr, C., Glaser, J. \& Sandström, M. Inorg. Chim. Acta 131, 153-156 (1987).

2. Nilsson, J., Bernhardt, P., Skarnemark, G., Maecke, H. \& Forssell-Aronsson, E. Eur. J. Nucl. Med. Mol. Imaging 33, S149 (2006).

3. Pena, B., Barhoumi, R., Burghardt, R. C., Turro, C. \& Dunbar, K. R. J. Am. Chem. Soc. 136, 7861-7864 (2014). 